\title{
Haemoperitoneum caused by a dissecting aneurysm of the left gastro- epiploic artery
}

\author{
William R. G. GibB* \\ M.B. B.S. \\ Timothy J. ARCHER $\dagger$ \\ F.R.C.S. \\ JON D. VAN DER WALT $\ddagger$ \\ M.B., B.Ch. (Wits). \\ *Department of Thoracic Medicine, Colindale Hospital, London NW9 5HG and Departments of \\ $\dagger$ General Surgery and $\ddagger$ Histopathology, Chase Farm Hospital, Enfield, Middlesex EN2 8JL
}

\begin{abstract}
Summary
A dissecting aneurysm of the left gastro-epiploic artery in a 79-year-old woman ruptured spontaneously into the peritoneal cavity. The insidious onset and the later progression to shock is discussed with relevance to the likely diagnoses. At laparotomy the aneurysm was excised.
\end{abstract}

\section{Introduction}

A ruptured splanchnic artery aneurysm is a rare cause of haemoperitoneum (Browne and Glashon, 1965). Fifty-eight per cent. of splanchnic artery aneurysms are found in the splenic artery (Stanley et al., 1970). The authors have found only four previous reports of a left gastro-epiploic artery aneurysm (Michas, Pollak and Wolfman, 1977).

\section{Case report}

A 79-year-old woman was admitted to hospital suffering from abdominal pain and vomiting. The pain had started in the epigastrium $12 \mathrm{hr}$ earlier, and radiated to both shoulders. She was being treated for atrial fibrillation and hypertension with digoxin, diuretics and methyldopa.

She was neither pyrexial nor shocked (BP 140/ $70 \mathrm{mmHg}$ ). The upper abdomen was slightly tender and bowel sounds were heard. Her haemoglobin concentration was $10.8 \mathrm{~g} / \mathrm{dl}$, the white cell count $14 \times 10^{9} / 1$ and the serum amylase was normal. Cholelithiasis was diagnosed and she was treated conservatively.

During the next twelve hours the pain increased and she became shocked (BP $100 / 60 \mathrm{mmHg}$ ) with generalized peritonitis. This was now thought to be caused by mesenteric ischaemia and after energetic resuscitation a laparotomy was performed.

Two litres of blood were present in the abdominal cavity and a haematoma was found high in the greater omentum, associated with a ruptured aneurysm of the left gastro-epiploic artery. Four centimetres of artery were excised between ligatures. The patient subsequently made a good recovery.

The specimen showed rupture of a dissecting aneurysm. Sections of the artery were stained with haematoxylin and eosin, Miller's elastic technique and the Alcian blue-van Giesson technique. The latter revealed foci of mucoid medial degeneration (Symmers, 1976).

\section{Discussion}

Dissecting aneurysms are found in association with hypertension, mucoid medial degeneration, pregnancy and trauma. Saccular and fusiform aneurysms, which are associated with atherosclerosis, arise more frequently than aneurysms which dissect the artery. A slow blood leak is more likely to arise from the rupture of a dissecting aneurysm than from the rupture of a saccular aneurysm, which often bursts catastrophically. It is therefore not surprising that fewer splanchnic arterial aneurysms present clinically than are discovered at post-mortem, either incidentally or as the main cause of death (Guthrie and Maclean, 1972).

In the first twelve hours this patient experienced localized upper abdominal pain with some tenderness and in the next twelve hours developed further abdominal pain and shock. This illustrates the slow bleed that can occur with rupture of a small dissecting arterial aneurysm and that the slow and spontaneous development of haemoperitoneum in the absence of a history of trauma may present diagnostic problems. In elderly patients, familiar conditions such as cholelithiasis, ischaemic colitis 
or diverticulitis which may present in similar fashion are most likely to be considered.

\section{Acknowledgment}

The authors wish to thank Mr W. W. Richardson for permission to report this case.

\section{References}

Browne, M.K. \& Glashan, R.W. (1965) Abdominal apoplexy. British Journal of Surgery, 52, 362.
Guthrie, W. \& Maclean, H. (1972) Dissecting aneurysms of arteries other than the aorta. Journal of Pathology, 108@ 219.

Michas, C.A., Pollak, E.W. \& Wolfman, E.F. (1977) Haemoperitoneum due to spontaneous gastro-epiploices artery rupture. Journal of the American Medical Associa $-\overrightarrow{-}$ tion, 237, 2526.

Stanley, J.C., Thompson, N.W., Fry, W.J. \& Arbor, A (1970) Splanchnic artery aneurysm. Archives of Surgery, $101,689$.

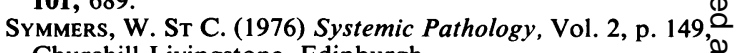
Churchill Livingstone, Edinburgh.

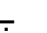

